\title{
LA CONTRIBUCIÓN DE LAS COOPERATIVAS DE AHORRO Y CRÉDITO AL DESARROLLO LOCAL EN QUERETARO, MÉXICO
}

POR

Graciela LARA GÓMEZ ${ }^{1}$ y

Amalia RICO HERNÁNDEZ ${ }^{2}$

\section{RESUMEN}

A partir de una aproximación teórica y empírica a las empresas sociales y su rol en el desarrollo local, se buscó establecer cómo las cooperativas de ahorro y crédito constituyen una estrategia pertinente para el avance social y económico de las comunidades mexicanas. Para tal efecto se recurrió al método cualitativo utilizando la estrategia de estudio de caso, seleccionando cuatro organizaciones ubicadas en zonas clasificadas como de alta marginación de acuerdo con indicadores oficiales en México. Los casos corresponden a cooperativas fundadas con la participación de miembros de la iglesia católica y cuya actividad financiera ha sido fundamental en el ámbito local en el que funcionan. Los resultados muestran que la organización de cooperativas, la acción voluntaria de sus miembros y en algunos casos el apoyo del Estado, constituyen instrumentos eficaces en la promoción del desarrollo local. Los principales beneficios en favor de los asociados se traducen en el otorgamiento de créditos y de servicios adicionales como becas educacionales y servicios de salud. Pudo constatarse, que con la práctica de los principios y valores del cooperativismo se facilita el trabajo en equipo y los asociados desarrollan habilidades emprendedoras y directivas que los benefician individual y colectivamente mejorando su calidad de vida.

\footnotetext{
${ }^{1}$ Profesora investigadora de la Facultad de contaduría y Administración. Universidad Autónoma de Querétaro. Dirección de correo electrónico: glara@uaq.mx.

${ }^{2}$ Profesora investigadora de la Facultad de contaduría y Administración. Universidad Autónoma de Querétaro. Dirección de correo electrónico: amaliarico@yahoo.com.mx.

REVESCO N 106 - Tercer Cuatrimestre 2011 - ISSN: 1885-8031 - www.ucm.es/info/revesco
}

DOI: 10.5209/rev_REVE.2011.v106.37376

Fecha de recepción: 28/07/2010

Fecha de aceptación: 18/01/2011 
Palabras clave: comunidades, marginación, estrategia, progreso social y económico.

Claves ECONLIT: O160, R110, P130.

\title{
THE CREDIT SAVING COOPERATIVE'S CONTRIBUTION TO THE MEXICAN LOCAL DEVELOPMENT
}

\begin{abstract}
From an empiric and theoretical approach to the social enterprises and its role at the local development, it was sought to establish how the credit and saving cooperatives are a pertinent strategy for the economic and social advance from the Mexican communities. For this purpose the qualitative method was used to utilize the study case strategy; it were selected four organizations located in classified areas as high marginalization according to the official Mexican indicators. The cases are cooperatives founded with the participation from members of the Catholic Church and whose financial activity has being fundamental at their local scope. The results demonstrate that the organization of cooperatives, the voluntary action from his members and in some cases the state support are effective tools at the local development promotion. The main benefits for the members are translated in the grant credits and additional services as educative scholarships and health services. It was verified that with the practice of the principles and cooperatives values facilitate the teamwork and the members develop entrepreneurial skills and directives that individually and collectively benefits them, improving their quality of life.
\end{abstract}

Keywords: communities, marginalization, strategy, social and economic progress.

REVESCO No 106 - Tercer Cuatrimestre 2011 - ISSN: 1885-8031 - www.ucm.es/info/revesco 


\section{INTRODUCCIÓN}

Para algunos la marginación es estudiada a través de los factores más importantes que conducen a ella, la pobreza (Campoy, 2002); para otros es la marginación el fenómeno que marca el camino hacia la pobreza. Como un fenómeno multidimensional la pobreza representa una privación de naturaleza importante, sus dimensiones se manifiestan por la carencia de ingresos, salud, educación, empoderamiento y condiciones laborales (Goldin y Reinert, 2007); mientras que la marginación es "un fenómeno que se origina en la modalidad, estilo o patrón histórico de desarrollo; que se expresa, por un lado, en la dificultad para propagar el progreso técnico en el conjunto de la estructura productiva y en las regiones del país, y por el otro, en la exclusión de grupos sociales de desarrollo y del disfrute de sus beneficios" (Anzaldo y Prado, 2005: 11).

Poseer una vivienda digna, educación básica, obtener ingresos por trabajo y vivir en una población accesible, son características deseables para los que carecen de lo más elemental. En el informe sobre Índices de Marginación, Anzaldo y Prado (2005) han señalado que la frágil estructura de oportunidades sociales, expone a privaciones, riesgos y vulnerabilidad que quedan fuera del control de los habitantes y cuya reversión requiere de la participación de los actores públicos, privados y sociales.

Para revertir los efectos nocivos de la marginación, el gobierno y otros actores sociales han instrumentado estrategias relacionadas con la creación de empresas sociales, que en su mayoría se han legitimado a través de cooperativas, cuyos integrantes basan sus prácticas en la filosofía cooperativa. Estas organizaciones juegan un papel relevante en el desarrollo local, ya que a través de ellas es posible llevar a cabo actividades para el beneficio de las personas que integran una comunidad, organizándose en torno a la gestión empresarial que no tiene como razón principal la maximización de ganancias, sino la satisfacción de ciertos objetivos económicos y sociales. Su creación y puesta en marcha favorece la inserción social y laboral entre los sectores más desprotegidos, atenuando la marginación y pobreza mediante la producción de bienes o servicios.

REVESCO No 106 - Tercer Cuatrimestre 2011 - ISSN: 1885-8031 - www.ucm.es/info/revesco 
México es un país donde viven 107.6 millones de habitantes, está organizado territorialmente en 31 Estados y un Distrito Federal; sus Estados se integran por municipios y éstos por localidades. Se ha estimado que 50.6 millones de mexicanos viven en pobreza de patrimonio, lo que representa el 47.4 por ciento del total de habitantes del país; el 18.2 por ciento es pobre alimentario, esto quiere decir casi 19.5 millones de personas que no tienen posibilidades de adquirir una canasta básica; y el 25.1 por ciento de los habitantes es pobre de capacidades, esto es 26.7 millones de personas, indicando que no cuentan con los recursos mínimos para satisfacer necesidades de alimentación, salud y educación (CONEVAL, 2008).

En el estudio se buscó establecer si las cooperativas de ahorro y crédito ${ }^{3}$ constituyen una estrategia de desarrollo local pertinente para el avance social y económico de las comunidades mexicanas. Para cumplir con el objetivo, en un primer momento se presenta un marco teóricoconceptual acerca del desarrollo local y las cooperativas, para luego contextualizar la situación que ha prevalecido en las regiones clasificadas como marginadas de acuerdo con indicadores oficiales mexicanos, para luego contrastarlos con la evidencia empírica recabada a través de los casos de estudio, con todo ello fue posible establecer las aportaciones de las cooperativas de ahorro y préstamo al desarrollo local de las comunidades marginadas del Estado de Querétaro, México.

\section{UNA VISIÓN TEÓRICA DEL DESARROLLO LOCAL Y DE LAS COOPERATIVAS DE AHORRO Y PRÉSTAMO}

Stiglitz (2006: 49) ha señalado que "la mayoría de nosotros vivirá de manera local: en nuestras comunidades, estados o países. Pero la globalización significa que al mismo tiempo, formaremos parte de una comunidad global", tal afirmación conduce a reflexionar en que respondiendo a necesidades inmediatas de los participantes y sentando las bases para organizar estrategias de desarrollo, las experiencias más relevantes de empresa social han comenzado como

\footnotetext{
${ }^{3}$ La denominación de las cooperativas de ahorro y crédito de acuerdo con la legislación mexicana es la de cooperativa de ahorro y préstamo. Además se les conoce como cooperativas financieras, cajas de ahorro y préstamo, cooperativas de ahorro y crédito popular o cajas de ahorro. En el presente documento se utilizarán indistintamente las denominaciones cooperativa de ahorro y crédito y cooperativa de ahorro y préstamo.
}

REVESCO No 106 - Tercer Cuatrimestre 2011 - ISSN: 1885-8031 - www.ucm.es/info/revesco 
iniciativas locales en circunstancias sumamente adversas, pero que con el paso del tiempo han trascendido sus fronteras demostrando su eficacia en la solución de problemas comunes.

¿Qué es el desarrollo local? el concepto de desarrollo a menudo es confundido con la expresión crecimiento que tiene una connotación de tipo cuantitativo relacionado con el incremento de la riqueza. El desarrollo incluye al crecimiento (Prévost, 1996; Sanchis, 1999) pero con un enfoque de tipo cualitativo que involucra a la sociedad en su conjunto y que se refiere al incremento del bienestar y al cambio en la estructura económica. Ante los dilemas que se generan como consecuencia de vivir en contextos globalizados, la pobreza es ahora una realidad global que requiere de soluciones locales; en este sentido Arocena (1995) ha señalado que lo local se ha concebido como "el remedio universal de todos los males" (p.14) afirmando que su definición no es tarea fácil. En este sentido el Diccionario de la Lengua Española (2001: 1) define a lo local como: "perteneciente o relativo a un territorio, a una comarca o a un país".

Diversos autores como Stiglitz (2006), Lafleur (2005), Sanchis (1999) y Arocena (1995) han evidenciado el renovado interés que se ha suscitado en torno al desarrollo local como una estrategia viable para enfrentar los efectos negativos que han derivado de la globalización y de los modelos económicos dominantes. Prévost (1996) lo define como "un proceso endógeno, emergente que surge de las iniciativas y el dinamismo de las comunidades locales" (p. 29), en su construcción revaloriza las prácticas imaginativas, la iniciativa empresarial, el dinamismo de las comunidades locales, despertando comportamientos innovadores centrados en la responsabilidad, creatividad y el espíritu empresarial. Por su parte, Alburquerque (2004: 170) aporta al debate el concepto de desarrollo económico local definiéndolo como: "un enfoque alternativo al de las políticas asistenciales de superación de la pobreza, y que busca incidir en la generación de empleo e ingresos mediante la mejora de la productividad y competitividad de los diferentes sistemas productivos locales".

Concibiendo al desarrollo local como un paradigma alternativo Cárdenas (2002) plantea la descentralización político-administrativa como uno de los elementos necesarios para el desarrollo local. En este sentido Prévost (1996) plantea que más que pensar en la descentralización como un proceso político, es necesario establecer las estrategias que 
conducirían a la creación y perennidad de un proyecto de desarrollo local lo que involucra la modificación en la cultura, en la mentalidad y en la manera de hacer las cosas.

\subsection{Las cooperativas de ahorro y préstamo en el desarrollo local}

Las empresas sociales -como las cooperativas- han operando en entornos locales, contribuyendo a la resolución de problemáticas comunes que con el transcurso del tiempo se han convertido en prácticas ejemplares dignas de reproducir, por lo que se reconoce que en los procesos de desarrollo local que involucran la participación de cooperativas, es de importancia central la dimensión identitaria de los socios, pues no sería posible pensar en la existencia de procesos exitosos sin una identidad fuerte que estimule y estructure el potencial de iniciativas de una comunidad (Arocena, 1995).

Las empresas de economía social, otorgan un enfoque innovador al desarrollo local, pues cuentan con una estrategia multidimensional de desarrollo, que amplía la estructura de la economía local y del mercado laboral respondiendo a nuevas necesidades (Noya, 2007). En ellas debe contemplarse la estructuración de un proyecto de desarrollo local, que cuente con la participación de las personas que comparten necesidades comunes, la intervención del Estado como impulsor de una mejor gestión económica, así como la participación de los actores privados y sociales.

Lafleur (2005) destaca la relevancia de la empresa cooperativa, cuya actuación generalmente se ha desplegado en una dinámica local, para luego vincularse al ámbito nacional e internacional mediante actividades de producción y servicios. Muestra de ello son las cooperativas de ahorro y crédito que pueden ser ejemplificadas a través de la fundación de las primeras cooperativas de crédito en Alemania a mediados del siglo XIX como una respuesta ante las nocivas consecuencias de la revolución industrial (DGRV, 2009). Igualmente importantes han sido las experiencias canadienses como la iniciada por Alphonse Desjardins en 1900, quien junto con un grupo de artesanos propuso el combate a la usura, estableciendo la Caisse Populaire de Lévis, dedicada al ahorro y crédito. Actualmente Desjardins y Raiffeisen son influyentes grupos financieros cooperativos que compiten con el sector bancario no cooperativo.

REVESCO No 106 - Tercer Cuatrimestre 2011 - ISSN: 1885-8031 - www.ucm.es/info/revesco 


\subsection{Las cooperativas de ahorro y préstamo en México}

Es precisamente de la experiencia canadiense que surgen las cajas populares, como el antecedente más cercano a las cooperativas de ahorro y préstamo mexicanas. No obstante, con anterioridad se habían tenido experiencias poco exitosas, como las que destaca Rojas (1984) quien señala que las cajas de ahorro tuvieron su antecedente en las cajas de comunidades indígenas, que de acuerdo con Jáuregui (2008) fueron creadas con la aprobación del Rey de España a finales de siglo XVIII y principios del XIX. En las cajas se resguardaban los depósitos que hacían los pueblos indios para sus emergencias, con el transcurso del tiempo se cometieron grandes abusos por quienes las administraban y aunque se trató de reorganizarlas fue prácticamente imposible por la cantidad de irregularidades en su administración. Otra de las organizaciones surgidas en el siglo XIX que luego desapareció con la guerra de independencia fueron los pósitos que se fundaron con fines caritativos y que tenía el objeto de socorrer a los indigentes. Entre 1841 y 1846 se crearon sin mucho éxito las cajas de ahorro que sirvieron para apoyar las carencias de los obreros y necesitados. A mediados del siglo XX fueron fundadas por la iglesia católica las cajas populares, que son el antecedente de las actuales cooperativas de ahorro y préstamo.

Para conocer la actualidad de las cooperativas de ahorro y préstamo es necesario contextualizar la situación que prevalece en el sistema financiero mexicano, que de acuerdo con el Banco de México (2010) está integrado por la banca múltiple como el principal intermediario financiero, la que se conforma de 41 instituciones que participan del 50.4 por ciento de los activos totales del sistema. El sector financiero popular se compone de 93 entidades de ahorro y crédito popular autorizadas por la Comisión Nacional Bancaria y de Valores (CNBV), participando con el 0.7 por ciento de los activos del sistema financiero, así como 183 entidades entre las que se cuentan a las uniones de crédito y otras de naturaleza afín que participan con el 0.6 por ciento de los activos totales (Tabla 1 ).

REVESCO No 106 - Tercer Cuatrimestre 2011 - ISSN: 1885-8031 - www.ucm.es/info/revesco 
Tabla 1

Estructura del Sistema Financiero Mexicano

\begin{tabular}{lcc}
\hline & $\begin{array}{c}\text { Número de } \\
\text { entidades }\end{array}$ & $\begin{array}{c}\text { Participación de los activos } \\
\text { totales (en por ciento) }\end{array}$ \\
\hline Banca múltiple & 41 & 50.4 \\
Afores (Administradoras de Fondos para el Retiro) ) $^{2 /}$ & 15 & 13.4 \\
Operadoras de sociedades de inversión & $3 /$ & 11.4 \\
Instituciones de fomento & $4 /$ & 9.6 \\
Aseguradoras & 61 & 6.2 \\
Casas de bolsa & 10 & 4.1 \\
Sociedades Financieras de Objeto Limitado (Sofoles) & 1,704 & 3.5 \\
y Sociedades Financieras de Objeto Múltiple \\
(Sofomes) \\
Entidades de ahorro y crédito popular \\
Otras instituciones financieras
\end{tabular}

Los datos mostrados parecerían desalentadores, sin embargo debe considerarse que existen organizaciones dedicadas al financiamiento popular con más de cincuenta años de permanencia en el mercado y que se encuentran en proceso de autorización por la CNBV; entre ellas se incluye a entidades como: cooperativas de ahorro y préstamo, sociedades de ahorro y préstamo, cajas solidarias, uniones de crédito y otras entidades sin figura jurídica.

REVESCO No 106 - Tercer Cuatrimestre 2011 - ISSN: 1885-8031 - www.ucm.es/info/revesco 
En cuanto a datos estadísticos del sector presentados por el Banco Mundial, se ha estimado que para 2002 se encontraba integrado por 2.6 millones de personas y 1.78 mil millones de dólares en activos, asociados a 657 entidades, entre las que se incluía a 157 cooperativas, 247 cajas populares (en ese entonces sin figura jurídica), así como 210 cajas solidarias que representaban más del 93 por ciento del sector financiero popular (Bansefi, 2002). La mayor presencia en socios de cooperativas de ahorro y préstamo se encuentra en el centro del país, ubicando en primer lugar al Estado de Guanajuato con 692 578, en segundo a Querétaro con 336 577 y en tercer lugar al Estado de Jalisco con 272 565; información reciente de la Comisión Nacional Bancaria y de Valores (2010) indica que se cuenta con 488 sociedades autorizadas para operar y que el sector ha crecido más de 6 mil millones de dólares en activos y 6.1 millones de asociados y clientes.

Como parte del proceso de autorización de las cooperativas de ahorro y préstamo, se han establecido en la Ley para Regular las Actividades de las Sociedades Cooperativas de Ahorro y Préstamo (2009) cinco niveles de operación, un nivel básico para cooperativas pequeñas y cuatro más para las que posean más de 3.5 millones de UDIS (Unidades de Inversión) de activos contables. El nivel de operaciones indica la capacidad financiera que una organización tiene para realizar operaciones con terceros y se mide en función del monto de los activos totales y el número de socios (Tabla 2).

Tabla 2

Nivel de operaciones de las cooperativas de ahorro y préstamo

\begin{tabular}{clr}
\hline Nivel de operaciones & Activos en UDIS $^{1 /}$ & \multicolumn{2}{c}{$\begin{array}{c}\text { Monto en miles de dólares de } \\
\text { Estados Unidos }\end{array}$} \\
\hline Básico & Menos de 2.5 millones & 890 \\
I & 3.5 millones & 1246 \\
II & 10 y 50 millones & Entre 3560 y 17801 \\
III & 50 y 250 millones & Entre 17 801 y 89005 \\
IV & Más de 250 millones & Más de 89005 \\
\hline
\end{tabular}

1/ Se consideró la cotización de la UDI y el dólar al 30 de septiembre de 2010.

Fuente: Ley para Regular las Actividades de las Sociedades Cooperativas de Ahorro y Préstamo (2009).

Con excepción de las organizaciones del nivel básico, las cooperativas requieren la autorización de la CNBV para llevar a cabo sus operaciones financieras, además deben pertenecer a una federación para que a través de ella se realice la supervisión auxiliar, así como

REVESCO No 106 - Tercer Cuatrimestre 2011 - ISSN: 1885-8031 - www.ucm.es/info/revesco 
aportar al fondo de protección que es administrado por la confederación de cooperativas de ahorro y préstamo.

\section{LOS OBJETIVOS Y EL MÉTODO DE ESTUDIO PARA EL ANÁLISIS DE LAS COOPERATIVAS DE AHORRO Y PRÉSTAMO}

La investigación se efectúo durante los años de 2008 y 2009, a través de un estudio transversal en el que se recurrió a la estrategia metodológica cualitativa de estudio de caso (Yin, 1984). Con el método fue posible realizar un acercamiento holístico a las realidades estudiadas, poniendo énfasis en la comprensión de los datos en el contexto que se presentaron e identificando las interrelaciones que surgieron en cada caso. Por tratarse de una investigación cualitativa no se pretendió llegar a generalizaciones, sino más bien obtener evidencias de la realidad en la que se desenvuelven las cooperativas de ahorro y préstamo y su rol en el desarrollo local de las comunidades marginadas.

Para el diseño metodológico se partió de la pregunta central ¿Cómo las cooperativas de ahorro y préstamo constituyen una estrategia pertinente para el avance social y económico de las comunidades mexicanas? El objetivo general fue establecer si las cooperativas de ahorro y crédito representan una estrategia de desarrollo local pertinente para el avance social y económico de las comunidades marginadas; en tanto que los objetivos específicos quedaron referidos a: contextualizar la situación de las comunidades en el Estado de Querétaro, considerando las dimensiones de la marginación; así como apreciar los beneficios económicos y sociales que han producido las cooperativas de ahorro y préstamo con la creación de fuentes de empleo, el financiamiento que autorizan a sus socios y el otorgamiento de otros beneficios de carácter social.

Para identificar los municipios marginados en el Estado de Querétaro, se recurrió a los Índices de Marginación 2005 del Consejo Nacional de Población (CONAPO) que establecen una clasificación en cinco grados (muy alto, alto, medio, bajo y muy bajo) (Figura 1). A través de los índices, es posible medir el impacto de las carencias entre la población como resultado de la imposibilidad de acceder a la educación primaria, habitar viviendas inadecuadas, percibir 
ingresos bajos y residir en localidades pequeñas y aisladas, lo que en su conjunto limita el pleno desarrollo de las capacidades humanas. Las dimensiones estructurales de la marginación son medidas a partir de nueve formas de exclusión social (Anzaldo y Prado, 2005).

\section{Figura 1}

Dimensiones de la Marginación

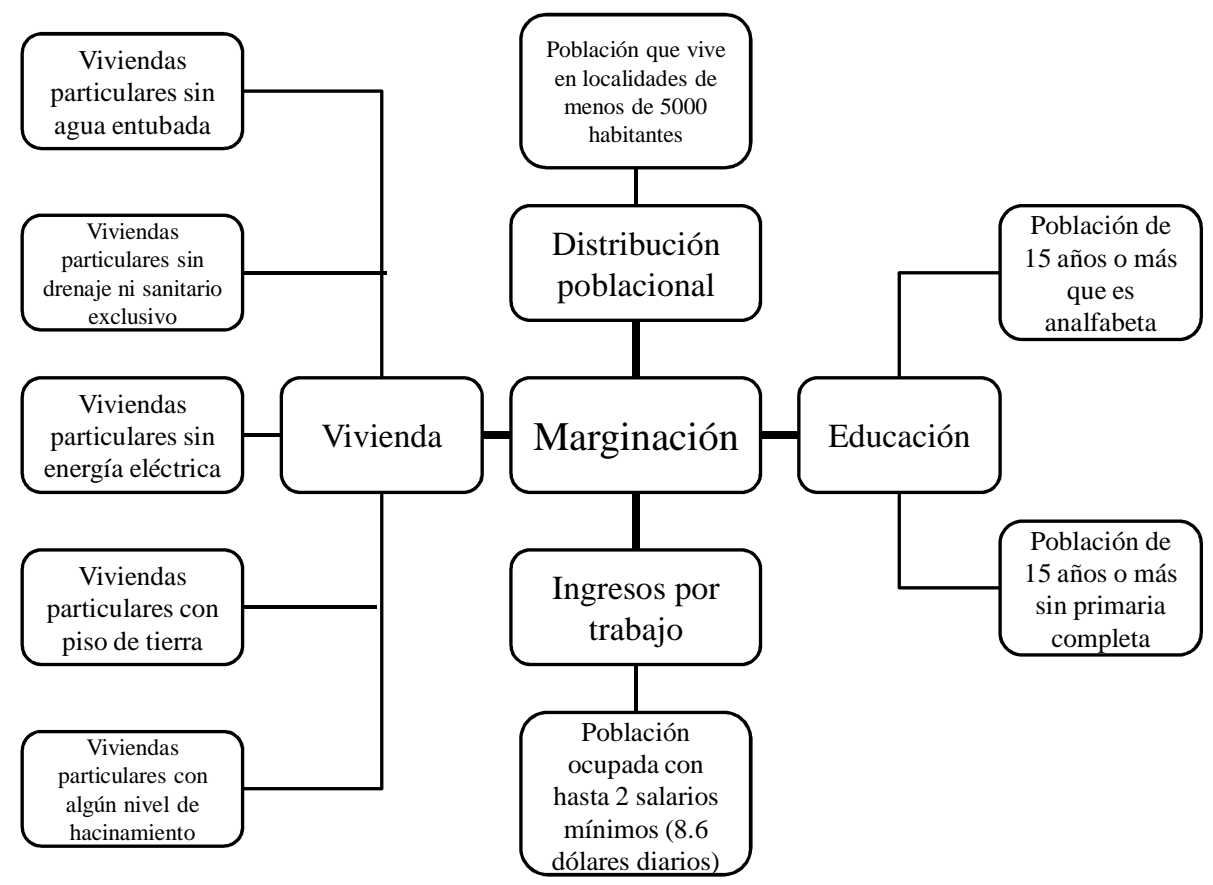

Fuente: Elaborado con base en el esquema conceptual de la marginación (Anzaldo y Prado, 2005: 15).

Los casos de estudios son explicativos (Yin, 1984) en tanto que aportan elementos para dar respuesta a la pregunta central de cómo sucede el fenómeno, permitiendo profundizar en la visión de los actores involucrados. Por tanto, se puso énfasis en la comprensión de los datos en el contexto que se presentaron, para su recolección se emplearon técnicas de investigación como: la entrevista semiestructurada, la observación directa y participante, así como el uso de la técnica de investigación documental. Las entrevistas se efectuaron con directivos del consejo de administración, gerentes y empleados; la observación directa se llevó a cabo en los domicilios sociales de las cooperativas, la observación participante se realizó en reuniones con directivos y socios de uno de los casos y en lo que corresponde al análisis de documentos los mismos se

REVESCO N 106 - Tercer Cuatrimestre 2011 - ISSN: 1885-8031 - www.ucm.es/info/revesco 
refirieron a los derivados de la operación, a las actas constitutivas y del consejo de administración.

\subsection{La selección de los casos de estudio}

El Estado de Querétaro está integrado por 18 municipios, uno de ellos altamente marginado nueve clasificados como de alta marginación y el resto en nivel medio, bajo y muy bajo; cuenta con una población de 1598139 habitantes y tiene un grado de marginación medio ocupando el lugar 17 de entre las 31 entidades federativas y el Distrito Federal de que se compone la República mexicana. En los diez municipios marginados vive el 17 por ciento de la población del Estado que se caracteriza por su marcada presencia indígena y su ubicación en localidades geográficamente dispersas (Tabla 3).

Tabla 3

Municipios Marginados del Estado de Querétaro, México

\begin{tabular}{clrc}
\hline $\begin{array}{c}\text { Lugar que Ocupa en el } \\
\text { Contexto Estatal }\end{array}$ & \multicolumn{1}{c}{ Municipio } & Población Total & Grado de Marginación \\
\hline 1 & Pinal de Amoles & 25325 & Muy alto \\
2 & San Joaquín & 7634 & Alto \\
3 & Amealco de Bonfil & 56457 & Alto \\
4 & Landa de Matamoros & 18905 & Alto \\
5 & Peñamiller & 17007 & Alto \\
6 & Arroyo Seco & 12493 & Alto \\
7 & Tolimán & 23963 & Alto \\
8 & Cadereyta de Montes & 57204 & Alto \\
9 & Huimilpan & 32728 & Alto \\
10 & Jalpan de Serra & 22025 & Alto \\
& Población total marginada en el Estado & 273714 & \\
& de Querétaro & 137821 & \\
\hline & Población total en los municipios donde & 1598139 & \\
\hline
\end{tabular}

Fuente: Estimaciones del CONAPO con base en el II Conteo de Población y Vivienda 2005 y Encuesta Nacional de Ocupación y Empleo 2005 (IV Trimestre).

Para la selección de los casos en principio se recabó información relacionada con las acciones del gobierno para atenuar la pobreza, que principalmente se basan en programas sociales federales y estatales que incluyen la creación de empresas sociales. Se revisó además información 
de empresas sociales formadas en los años previos al inicio de la investigación, estableciendo que los apoyos gubernamentales se han venido canalizando a través del Fondo Nacional de Apoyos para Empresas en Solidaridad (FONAES) y la Secretaría de Desarrollo Sustentable (SEDESU). FONAES es operado por instancias federales y tiene por objeto el desarrollo del sector productivo de las organizaciones sociales y comunidades en extrema pobreza, con la finalidad de generar oportunidades de empleo y mejora en ingresos para la población de menores recursos. Por su parte SEDESU funciona en el contexto local, concentrándose en la promoción de programas de fomento a la micro, pequeña y mediana empresa con el objetivo de desarrollar la capacidad de los empresarios generando oportunidades de negocio. La aplicación de los programas no ha tenido un impacto significativo en la economía de los municipios queretanos, pues con los apoyos se han formado pequeñas cooperativas de producción que carecen de una adecuada estructura organizativa.

Con lo anterior, se determinó que las empresas creadas a partir de apoyos gubernamentales no ofrecían casos de estudio apropiados para cumplir con los objetivos propuestos en la investigación, por lo que fue necesario buscar otro tipo de empresas sociales. Los casos potenciales fueron localizados en siete de los municipios con mayor grado de marginación, que corresponden a cuatro cooperativas que tienen su domicilio social en los municipios de Pinal de Amoles, San Joaquín, Amealco de Bonfil y Peñamiller; y donde además una de las cooperativas cuenta con sucursales en Jalpan, Arroyo Seco y Landa de Matamoros.

\subsection{Los casos de estudio y su ubicación en regiones marginadas}

Para la selección de los casos se tomó en consideración que las cooperativas de ahorro y préstamo ocupan el segundo lugar en número de socios en el contexto nacional, además de que tres de los casos tienen más de 45 años de experiencia y su trayectoria es reconocida por los habitantes de las comunidades en las que operan. Por las facilidades que fueron otorgadas para acceder a la información, fueron seleccionados cuatro casos de estudio correspondientes a las cooperativas de ahorro y préstamo denominadas: Caja Popular Pinal, Caja San Miguel Palmas, Caja Fátima y El Triunfo Ntöte. Las cooperativas se localizan en el Estado de Querétaro en municipios clasificados como de alta y muy alta marginación, sus características más relevantes 
vinculadas con la fundación de los municipios, número de habitantes y actividades económicas de las principales zonas en las que operan las cooperativas de ahorro y préstamo se describen en la Enciclopedia de los municipios de México (2009) y para los fines del documento se presentan algunas de ellas a continuación:

- Caja Popular Pinal. El nombre de Pinal de Amoles se deriva de la palabra náhuatl "amolli", sus primeros pobladores fueron recolectores y cazadores y se presume que su llegada se remonta al año 6000 a.C., siendo habitada la región por tribus chichimecas, pames y jonaces. El municipio posee un clima frío y húmedo con paisajes de cerros boscosos, cuenta con 203 localidades y 25325 habitantes. Las actividades económicas son: la agricultura, que incluye la siembra de maíz, fríjol, garbanzo, chile, papa y jitomate, así como la ganadería y la piscicultura. La cooperativa presta servicios en el semidesierto y otras localidades de la sierra queretana.

- Caja Fátima. La fundación de San Joaquín se debe a Jerónimo de Labra y al Padre Ochoa, quienes al llegar a un lugar conocido como Ranas, establecieron la misión de San Nicolás de Tolentino el 13 de noviembre de 1682, anteriormente la región fue habitada por indígenas Pames y Jonaces. Actualmente el municipio tiene una densidad demográfica baja con 7634 habitantes dispersados en 67 localidades, las actividades económicas son la agricultura y la minería.

- Caja San Miguel Palmas. Peñamiller significa "Piedras al Millar" o "Cerro de Peñascos", en el siglo XII estuvo habitada por indígenas pames y jonaces. El municipio fue fundado en 1748, actualmente cuenta con 17007 habitantes distribuidos en 139 pequeñas localidades, San Miguel Palmas cuenta con 640 habitantes. La fruticultura es una de las actividades primordiales del municipio, la venta de artesanías fundamenta la economía local así como la elaboración de productos naturales propios del semidesierto.

- Caja El Triunfo Ntöte. Amealco de Bonfil cuenta con 56457 habitantes distribuidos en 149 localidades, entre ellas destaca la localidad de San Ildefonso Tultepec que cuenta con 1920 habitantes. La actividad económica está concentrada en la agricultura, el comercio de artesanías, la agricultura y ganadería de subsistencia. Algunos indígenas se han incorporado al comercio informal, a la alfarería y extracción de sillar que es un material para la construcción, las mujeres se dedican a la producción de muñecas y otras artesanías. (Amealco de Bonfil, 2005).

REVESCO No 106 - Tercer Cuatrimestre 2011 - ISSN: 1885-8031 - www.ucm.es/info/revesco 


\section{RESULTADOS DEL ESTUDIO DE CASOS DE LAS COOPERATIVAS DE AHORRO Y PRÉSTAMO}

La información estadística del desempeño de las cooperativas de ahorro y préstamo estudiadas, así como su impacto en los socios es escasa; por lo que la argumentación que se expone en el documento muestra los resultados obtenidos del análisis cualitativo de los datos referidos a las mejoras sociales y económicas percibidas por los participantes en las cooperativas. Por tanto, en un primer momento se efectuó el análisis de las características relativas a la fundación de las cooperativas, número de socios, operaciones, domicilio social, habitantes y grado de marginación de las zonas donde las cooperativas prestan servicios financieros; para luego, retomar las dimensiones de la marginación a fin de evidenciar las acciones llevadas a cabo por las organizaciones en favor de sus socios y sus comunidades.

\subsection{Las características operativas y financieras de las cooperativas de ahorro y préstamo}

Atendiendo a la práctica de los preceptos de la filosofía del cooperativismo y contando con la participación de sacerdotes de la iglesia católica, las cooperativas de ahorro y préstamo Pinal, Fátima y San Miguel Palmas fueron fundadas a partir de 1961, 1963 y 1965 respectivamente; mientras que como parte de un plan de desarrollo local promovido por un grupo de religiosas de la comunidad de Asunción y una agencia de desarrollo local El Triunfo Ntöte se fundó en 2004.

Las cooperativas de ahorro y préstamo se establecieron en regiones históricamente rezagadas del desarrollo económico, por lo que sus actividades se enfocan a la atención de los sectores de la población con bajo nivel de ingresos y que tiene acceso limitado a los servicios bancarios. Con excepción de San Joaquín donde se ubica la Caja Fátima y tres sucursales de la Caja Pinal, en el resto de las localidades donde funcionan las cooperativas no existen instituciones bancarias. De entre las organizaciones estudiadas la Caja Popular Pinal es la más grande en cuanto a número de socios y activos, tiene 20000 socios distribuidos en 18 sucursales de tres estados de la república y para su funcionamiento ha sido autorizada por la CNBV; el resto de las cooperativas no requieren la autorización de la CNVB dado que se ubican en el nivel de 
operaciones básico y registran menos de 600 socios. Las cuatro organizaciones proporcionan servicios exclusivamente a personas físicas que tengan la calidad de socio (Tabla 4).

\section{Tabla 4}

Características de las cooperativas de ahorro y préstamo

\begin{tabular}{|c|c|c|c|c|c|c|}
\hline Cooperativa & $\begin{array}{l}\text { Año de } \\
\text { fundación }\end{array}$ & $\begin{array}{l}\text { Número } \\
\text { de socios }\end{array}$ & $\begin{array}{c}\text { Nivel de } \\
\text { operaciones } \\
2 /\end{array}$ & $\begin{array}{c}\text { Servicios } \\
\text { financieros que } \\
\text { proporciona }\end{array}$ & $\begin{array}{l}\text { Domicilio social } \\
\text { (Localidad y } \\
\text { municipio) }\end{array}$ & $\begin{array}{c}\text { Grado de } \\
\text { marginación } \\
\text { del } \\
\text { municipio } \\
\end{array}$ \\
\hline Caja Popular Pinal $^{1 /}$ & 1961 & 20,000 & III & $\begin{array}{l}\text { - Ahorro. } \\
\text { - Crédito. } \\
\text { - Depósitos de } \\
\text { inversión a plazo. } \\
\text { - Recepción de } \\
\text { remesas. }\end{array}$ & $\begin{array}{l}\text { Ahuacatlán, } \\
\text { Pinal de Amoles }\end{array}$ & Muy alto ${ }^{3 /}$ \\
\hline Caja Popular Fátima & 1963 & 200 & Básico & $\begin{array}{l}\text { - Ahorro. } \\
\text { - Crédito. }\end{array}$ & $\begin{array}{l}\text { San Joaquín, } \\
\text { Querétaro }\end{array}$ & Alto \\
\hline $\begin{array}{l}\text { Caja San Miguel } \\
\text { Palmas }\end{array}$ & 1965 & 600 & Básico & $\begin{array}{l}\text { - Ahorro. } \\
\text { - Crédito. }\end{array}$ & $\begin{array}{l}\text { San Miguel } \\
\text { Palmas, } \\
\text { Peñamiller }\end{array}$ & Alto \\
\hline El Triunfo Ntöte & 2004 & 340 & Básico & $\begin{array}{l}\text { - Ahorro. } \\
\text { - Crédito. }\end{array}$ & $\begin{array}{l}\text { San Ildefonso, } \\
\text { Amealco de } \\
\text { Bonfil }\end{array}$ & Alto \\
\hline
\end{tabular}

Fuente: Elaboración propia.

1/ Se cambio la denominación por razones de confidencialidad.

2/ De acuerdo con la Ley para Regular las Actividades de las Sociedades Cooperativas de Ahorro y Préstamo, el monto de activos en miles de dólares para el nivel III estará entre 17,801 y 89,005 y para el nivel básico 890.

3/ El domicilio social de la cooperativa ha sido clasificado como de muy alta marginación, opera además en tres municipios de alta marginación.

Las características financieras y operativas de las cooperativas son desiguales entre sí, la principal diferencia se vincula con la magnitud y diversificación de operaciones de la Caja Pinal, la cantidad de socios con la que cuenta y su ubicación en distintas localidades genera un mayor número de operaciones financieras, ya que además de efectuar transacciones de ahorro y préstamo recibe depósitos por inversiones a plazo fijo y recepción de remesas; en contraste el resto de las cooperativas no tienen sucursales y su diversificación de servicios financieros es limitada.

Los elementos relacionados con el desarrollo de las actividades financieras y de organización de las cooperativas se mencionan enseguida:

1. Con excepción de la Caja Popular Pinal que cuenta con nivel de operaciones III, el crecimiento en socios y activos de las otras cooperativas ha sido lento, entre otras

REVESCO N 106 - Tercer Cuatrimestre 2011 - ISSN: 1885-8031 - www.ucm.es/info/revesco 
circunstancias, por la dispersión geográfica de las comunidades más cercanas y por su política de prestar servicios exclusivamente a habitantes de la localidad y de zonas aledañas.

2. Para efectuar las operaciones financieras, en las cooperativas se utilizan principalmente los recursos depositados por los socios y los ahorradores menores; en El Triunfo Ntöte para el otorgamiento de créditos se recurre a un intermediario financiero, debido a que la mayor parte de la población no cuenta con ingresos fijos que les permitan ahorrar; por lo que se requiere de recursos externos para cubrir la demanda de financiamiento.

3. Las cooperativas no reciben apoyos o subvenciones del gobierno. Su capital social se integra de las aportaciones sociales que entregan los socios al ingresar. Excepcionalmente, con motivo de la apertura de la cooperativa El Triunfo Ntöte el gobierno local entregó una aportación económica única de poco más de 40000 dólares.

4. Las cooperativas habitualmente realizan operaciones de ahorro y crédito; en promedio el interés anualizado que se paga al ahorro es del 5 por ciento y el devengado por el crédito es del 24 por ciento anual. Además, la Caja Popular Pinal proporciona diferentes modalidades de crédito cobrando tasas de interés que van desde 1.1 por ciento hasta 2.5 por ciento mensual, también recibe depósitos a plazo fijo y remesas de los socios que laboran en Estados Unidos.

5. La cooperativa el Triunfo Ntöte para el otorgamiento de créditos organiza pequeños grupos denominados Grupos de Ayuda Mutua y Esfuerzo Propio (GAMEPS), que son los organismos de base de la cooperativa. Los que se integran con un mínimo de tres y hasta un máximo de diez personas (preferentemente mujeres) que responden de manera solidaria por el pago de los créditos otorgados; a través de los GAMEPS los socios solicitan los créditos en forma conjunta, los que son aplicados a proyectos productivos individuales. De acuerdo con los reglamentos y modalidades de crédito autorizadas, el resto de las cooperativas otorgan préstamos de manera individual al socio que lo solicita.

6. Por la magnitud de sus operaciones la estructura orgánica de la Caja Popular Pinal es más compleja, integrando en su organigrama un nivel directivo, cargos ejecutivos como una gerencia general, gerencias operativas, así como supervisiones y otros puestos de operación. El resto de las cooperativas tienen de uno a cuatro empleados que realizan múltiples funciones (administración, operación y mantenimiento de la oficina). En todas

REVESCO No 106 - Tercer Cuatrimestre 2011 - ISSN: 1885-8031 - www.ucm.es/info/revesco 
las cooperativas se presenta en el organigrama, a la asamblea general como el máximo órgano de gobierno, enseguida se ubica el nivel directivo que incluye a los consejos de administración, vigilancia y al comité de crédito.

7. Las fuentes de empleo generadas por las cooperativas son ocupadas por socios que habitan en las localidades donde se proporcionan los servicios financieros. En la Caja Popular Pinal, para algunos puestos como administración de riesgos e informática se contrata personal de otras regiones, ya que el perfil establece como requerimiento mínimo poseer conocimientos especializados comprobables a través de una carrera profesional.

8. En la gerencia de las cooperativas se ha tenido poca rotación del personal; las cooperativas Pinal, San Miguel Palmas y Fátima, han tenido a lo largo de su existencia de entre uno y tres gerentes. En El Triunfo Ntöte no se cuenta con el puesto de gerente, la única empleada con que se cuenta ostenta el puesto de encargada de la oficina.

Las cuatro organizaciones son consideradas por sus asociados como la opción más adecuada para acceder a los servicios financieros, dado que la mayor parte de la población no es sujeta de crédito en el sector bancario y en muchas de las localidades no existen tales servicios. Los miembros de las cooperativas reconocen que sus organizaciones cumplen con su función económica y social, procurando el bienestar de sus socios y de la comunidad con apego a la práctica de los principios y valores del cooperativismo.

\section{2. La contribución de las cooperativas de ahorro y préstamo en favor de las comunidades marginadas}

Para el desarrollo de este apartado se partió de que la generación de ingresos por trabajo es uno de los aspectos esenciales para establecer que las cooperativas coadyuvan al desarrollo local en las comunidades marginadas Por tanto, se consideró que la creación de fuentes de empleo a través de las cooperativas y la obtención financiamiento para la puesta en marcha de iniciativas empresariales, conducen a atenuar o incluso a eliminar las consecuencias indeseables de la marginación.

REVESCO No 106 - Tercer Cuatrimestre 2011 - ISSN: 1885-8031 - www.ucm.es/info/revesco 
En el análisis que se presenta se recurrió a las cuatro dimensiones de la marginación (ingresos por trabajo, educación, vivienda y distribución poblacional), para luego contrastarlas con la evidencia empírica y de esta forma obtener los elementos que han coadyuvado a mejorar el entorno social y económico de los participantes en las cooperativas.

\section{Ingresos por trabajo.}

De acuerdo con el indicador oficial referido a la obtención de ingresos por trabajo, cuando una persona percibe una cantidad inferior a los 8.6 dólares diarios se entiende que subsiste en condiciones de marginación, por lo que una de las vías para superar las carencias es acceder a un empleo adecuadamente remunerado o bien, generar su propio ingreso a través de la creación de micro empresas.

Entonces se consideró como un aspecto relevante la participación de la cooperativa en la creación de fuentes de trabajo para sus socios. Al respecto los empleados opinaron que sus cooperativas no son generadoras de empleo. Pues considerando que las cooperativas tienen presencia en municipios marginados de Querétaro y que la Caja Pinal posee sucursales otras entidades federativas; puede inferirse que las cuatro cooperativas proporcionan trabajo a una cantidad reducida de habitantes, dado que la oferta laboral total se limita a 112 fuentes de trabajo, correspondiendo a la Caja Popular Pinal 105 de ellas. Sin embargo, los empleados reconocen que obtener un trabajo en sus localidades es muy difícil, por lo que trabajar en una cooperativa de ahorro y préstamo es una buena oportunidad ya que las plazas de trabajo son permanentes y los sueldos son suficientes para sus necesidades.

Con relación a las remuneraciones laborales, además del salario se otorgan prestaciones establecidas en las leyes y otras adicionales (Tabla 5) que superan los dos salarios mínimos a que se refiere el indicador referido a población ocupada (8.6 dólares diarios); el sueldo más bajo equivale a tres salarios mínimos mientras que el más alto es superior los 15 salarios mínimos. Con excepción de la Caja San Miguel, en las cooperativas se registra a los trabajadores en los servicios obligatorios de salud y vivienda, y anualmente se otorgan a los trabajadores vacaciones con goce de sueldo, prima vacacional, aguinaldo. Aparte de lo señalado en la Caja Pinal se dan 
prestaciones adicionales como ayuda para la adquisición de despensas, becas educacionales, préstamos personales sin intereses y fondo de ahorro.

Tabla 5

Empleados y prestaciones laborales

\begin{tabular}{|c|c|c|c|c|c|}
\hline Cooperativa & $\begin{array}{l}\text { Número de } \\
\text { empleados }\end{array}$ & $\begin{array}{c}\text { Empleados con } \\
\text { más de dos } \\
\text { SMG }^{1 /}\end{array}$ & $\begin{array}{l}\text { Nivel escolar } \\
\text { promedio de } \\
\text { los empleados }\end{array}$ & $\begin{array}{c}\text { Prestaciones } \\
\text { legales }^{2 /}\end{array}$ & $\begin{array}{l}\text { Prestaciones } \\
\text { adicionales }^{3 /}\end{array}$ \\
\hline $\begin{array}{l}\text { Caja Popular Pinal } \\
\text { Caja Popular Fátima } \\
\text { Caja San Miguel } \\
\text { Palmas } \\
\text { El Triunfo Ntöte }\end{array}$ & $\begin{array}{c}105 \\
4 \\
2\end{array}$ & $\begin{array}{c}105 \\
4 \\
2\end{array}$ & $\begin{array}{c}\text { Preparatoria } \\
\text { Secundaria } \\
\text { Primaria }\end{array}$ & $\begin{array}{c}\mathrm{Si} \\
\mathrm{Si} \\
\text { Parcialmente }^{4 /}\end{array}$ & $\begin{array}{l}\mathrm{Si} \\
\mathrm{No} \\
\mathrm{No}\end{array}$ \\
\hline Total & 112 & 112 & & & \\
\hline \multicolumn{6}{|c|}{$\begin{array}{l}\text { Fuente: Elaboración propia. } \\
\text { 1/ SMG= Salario mínimo general de la zona económica a la que pertenece el Estado de Querétaro. Dos salarios } \\
\text { equivalen a } 8.6 \text { dólares diarios. } \\
\text { 2/ Las prestaciones legales, son los derechos que de acuerdo con las leyes vigentes tienen los trabajadores en materia } \\
\text { de aguinaldo ( } 15 \text { días de salario nominal por año trabajado), vacaciones y prima vacacional (de acuerdo con la } \\
\text { antigüedad del trabajador es de seis días por el primer año y se incrementa en dos días por cada año adicional de } \\
\text { servicios hasta el cuarto año, en lo sucesivo se incrementan dos días cada cuatro años; la prima vacacional es del } 25 \\
\text { por ciento calculado sobre los días de vacaciones). Además se otorgan servicios de seguridad social relacionados con } \\
\text { la salud (la cuota es pagada por el patrón si se paga un salario mínimo y si el pago es superior la cuota se paga entre } \\
\text { el patrón y el trabajador), prestaciones de vivienda (es pagada por el patrón) y seguro para el retiro (cuota pagada por } \\
\text { el patrón). } \\
\text { 3/ Las prestaciones adicionales se refieren a beneficios otorgados a los trabajadores como: despensas, becas } \\
\text { educacionales, préstamos personales y fondo de ahorro. } \\
\text { 4/ Los empleados no se encuentran inscritos en los servicios de seguridad social. }\end{array}$} \\
\hline
\end{tabular}

En las cooperativas se tiene baja rotación de personal y se mantienen políticas de contratar personal originario de las localidades donde se ubican las oficinas, aunque excepcionalmente en la Caja Popular Pinal se han seleccionado empleados de otras entidades; además se tiene la práctica de que el personal se convierta en socio al ser contratado lo que propicia un sentimiento de identidad con la organización, por ejemplo, en la gerencia de la Caja Fátima su titular ha permanecido laborando desde su fundación en 1963, en la Caja San Miguel Palmas han colaborado dos gerentes y en la Caja Pinal únicamente tres gerentes.

En El Triunfo Ntöte, las funciones de promoción y administración son realizadas por los directivos quienes son miembros distinguidos de la comunidad y que realizan sus actividades de manera voluntaria, cuentan con el apoyo de una empleada bilingüe que habla español y otomí,

REVESCO N 106 - Tercer Cuatrimestre 2011 - ISSN: 1885-8031 - www.ucm.es/info/revesco 
ella se encarga de entregar los créditos, organizar las reuniones, realizar las actividades de cobranza, organizar la capacitación en temas de cooperativismo y otras funciones administrativas.

En lo que se refiere al otorgamiento de créditos, en todos los casos se ha dinamizado la economía local a través de la solidaridad y ayuda mutua, que se manifiesta mediante la identificación de las necesidades económicas de los socios. Ello ha permitido establecer líneas de crédito con tasas de interés accesibles, privilegiando el financiamiento de proyectos productivos y los destinados a la adquisición, mejora o ampliación de las casas habitación de los socios.

Aunque se reconoce que una buena parte de los ingresos de la población proviene de las remesas de las personas que trabajan en el extranjero, las cooperativas son reconocidas por los beneficios que prestan a la población a través del financiamiento accesible, los directivos consideran que mediante el crédito se impulsa la creación y desarrollo de empresas locales, opinan que el principal aporte de las cooperativas es que se estimula el carácter emprendedor de los socios, pues se han creado micro empresas de diversas actividades con las que se ha fomentado el autoempleo y la creación de nuevas fuentes de trabajo lo que redunda en la mejora económica de los habitantes (Tabla 6).

Tabla 6

Iniciativas empresariales de los socios

\begin{tabular}{lll}
\hline $\begin{array}{c}\text { Cooperativa de ahorro y } \\
\text { préstamo }\end{array}$ & \multicolumn{1}{c}{ Tipo de empresas financiadas } \\
\hline Caja Popular Pinal & - & Actividades comerciales (abarrotes y otros giros del sector \\
& & alimenticio). \\
& - & Agricultura (maíz, frijol, chile y café). \\
& - & Ganadería. \\
& - & Micro empresas de servicios \\
\hline Caja Popular Fátima & - & Fabricación de jugo y licor de manzana. \\
& - & Cultivo de manzana. \\
& - & Servicios de hospedaje. \\
\hline Caja San Miguel Palmas & - & Actividades comerciales (abarrotes y otros giros del sector \\
& & alimenticio). \\
& - & Criaderos de peces. \\
& - & Agricultura (nuez y piñón). \\
& - & Micro empresas del sector mecánico. \\
\hline El Triunfo Ntöte & - & Comercio de alfarería. \\
& - & Elaboración de artesanías de barro y muñecas. \\
\hline Fuente: Elaboración &
\end{tabular}

Fuente: Elaboración propia.

REVESCO N 106 - Tercer Cuatrimestre 2011 - ISSN: 1885-8031 - www.ucm.es/info/revesco 
En San Miguel Palmas se efectúan anualmente jornadas de salud para los socios y la población en general. Con excepción de El Triunfo Ntöte en las cooperativas se proporciona a los socios el beneficio del seguro de vida, que consiste en la entrega a los herederos del socio fallecido un monto equivalente al ahorro que hasta antes de su deceso tuviera depositado el socio, además el monto del préstamo y los intereses devengados son condonados.

En lo que respecta a las labores que desarrollan los directivos, estos participan en funciones de representación, vigilancia y autorización de los créditos, su colaboración es de carácter voluntario; únicamente en la Caja Popular Pinal se cubren a los directivos los gastos de transporte por el traslado desde su comunidad hasta el lugar en donde se celebren las reuniones.

\section{Educación}

La escolaridad de la población constituye uno de los factores decisivos para aumentar la productividad del trabajo e incorporar la innovación tecnológica, fortaleciendo la competitividad y el acceso al conocimiento que es un aspecto esencial para que las personas puedan realizar un apropiado proyecto de vida. Los grados escolares en México inician con la educación preescolar (tres años), luego primaria (seis años), secundaria (tres años), preparatoria o bachillerato (tres años), licenciatura (cuatro a cinco años), maestría (dos años) y doctorado (tres años), o bien al concluir la educación preparatoria se puede acceder a una carrera técnica. En la dimensión educativa, se considera que una persona es marginada cuando no ha tenido acceso a la educación primaria o ésta ha quedado inconclusa.

Considerando que en las comunidades los rezagos más significativos se encuentran entre la población analfabeta de 15 años sin primaria concluida, en la dimensión relacionada con el acceso a la educación, se examinaron las acciones que las cooperativas han llevado a cabo para mejorar el nivel escolar de sus trabajadores, socios y de los habitantes en general. En este sentido pudo observarse que el nivel de educación difiere entre los trabajadores de las cooperativas estudiadas, el nivel escolar en San Miguel Palmas es de primaria, en El Triunfo Ntöte y Fátima es de secundaria y en Pinal es de preparatoria, en ésta última algunos empleados que tienen cargos de jefatura o gerencia poseen estudios de nivel licenciatura y maestría. Los apoyos que reciben 
los empleados para continuar su educación formal son limitados, únicamente en la Caja Popular Pinal se proporcionan becas parciales para el pago de colegiaturas para estudios de posgrado. Entre los beneficios que se otorgan a los ahorradores menores pueden mencionarse las becas que se otorgan a los ahorradores menores que obtienen buenas calificaciones en un ciclo escolar y que cumplan las disposiciones previstas en el reglamento que aprueba anualmente el Consejo de Administración.

Es de destacar las gestiones que han realizado los directivos de El Triunfo Ntöte y otros líderes de la comunidad para incorporar nuevas opciones educativas en San Ildefonso, ya que hasta antes de iniciar con el plan de desarrollo local únicamente se podía acceder a los niveles de educación preescolar, primaria y secundaria. Actualmente es una realidad el acceso a la educación preparatoria y profesional, a través de una carrera denominada Licenciatura en Emprendimientos de Economías Solidarias, que fue creada por una asociación civil que pertenece al grupo de cooperativas de la comunidad de San Ildefonso denominada Instituto Intercultural Ñöñho. A pesar que en el resto de las cooperativas de ahorro y préstamo no se realizan gestiones para incorporar nuevas opciones educativas, en todas ellas se imparten a los socios cursos de inducción, capacitación en principios y valores, cursos sobre proyectos productivos, manualidades y en temas relacionados con el uso adecuado de los créditos (Tabla 7).

Tabla 7

Programas educativos promovidos por las cooperativas

\begin{tabular}{|c|c|c|c|}
\hline $\begin{array}{c}\text { Cooperativa de ahorro y } \\
\text { préstamo }\end{array}$ & Otorgamiento de becas & $\begin{array}{l}\text { Programas de } \\
\text { capacitación }\end{array}$ & Programas educativos \\
\hline Caja Popular Pinal & $\begin{array}{l}\text { - Proporcionan becas a } \\
\text { empleados que estudian } \\
\text { posgrado. } \\
\text { - Otorgan becas a menores } \\
\text { ahorradores. }\end{array}$ & $\begin{array}{l}\text { - En principios y valores. } \\
\text { - Cursos de inducción. } \\
\text { - En proyectos productivos } \\
\text { y uso adecuado del } \\
\text { crédito. }\end{array}$ & - No se gestionan. \\
\hline Caja Popular Fátima & - No se otorgan. & $\begin{array}{l}\text { - En principios y valores. } \\
\text { - Cursos de inducción. } \\
\text { - En proyectos productivos } \\
\text { y uso adecuado del crédito }\end{array}$ & - No se gestionan. \\
\hline Caja San Miguel Palmas & - No se otorgan. & $\begin{array}{l}\text { - En principios y valores. } \\
\text { - Cursos de inducción. } \\
\text { - Cursos de manualidades. } \\
\text { - En proyectos productivos } \\
\text { y uso adecuado del crédito }\end{array}$ & - No se gestionan. \\
\hline El Triunfo Ntöte & - No se otorgan. & - En principios y valores. & - Gestión ante entidades \\
\hline
\end{tabular}

REVESCO No 106 - Tercer Cuatrimestre 2011 - ISSN: 1885-8031 - www.ucm.es/info/revesco 


\begin{tabular}{lll}
\hline & - Cursos de inducción. & gubernamentales de la \\
& - Integración de & preparatoria. \\
& GAMEPS. & - Creación de un programa \\
& - En proyectos productivos & de nivel licenciatura. \\
& y uso adecuado del crédito & \\
\hline
\end{tabular}

Fuente: Elaboración propia.

\section{Vivienda}

Considerando que la vivienda es el espacio afectivo y físico que comparte la familia y es determinante para el desarrollo de las capacidades de sus integrantes, poseer viviendas inadecuadas expone a las personas a vivir en precarias condiciones y a sufrir privaciones que les impiden un desarrollo saludable. Para el análisis de la dimensión que se refiere a habitar en viviendas inadecuadas, se analizaron las acciones que las cooperativas llevan a cabo en favor de sus trabajadores para procurar la mejora de sus viviendas, así como las políticas que se mantienen respecto al financiamiento destinado a la adquisición o mejora de casas - habitación.

En lo que corresponde a las prestaciones sociales a que tiene derecho un trabajador, el patrón está obligado a aportar bimestralmente al Fondo Nacional de Vivienda, a fin de que en un determinado periodo de tiempo el empleado a través de dicho fondo pueda acceder al financiamiento de una casa nueva. Se observó que en la Caja Popular Pinal los empleados han hecho uso del financiamiento a que tienen derecho, además de que utilizan la prestación adicional de préstamos personales para mejorar sus viviendas. En las demás cooperativas los empleados perciben que han mejorado su calidad de vida a partir de la mejora de sus casas habitación, lo han hecho posible gracias al sueldo que perciben. Cabe señalar que las viviendas de los trabajadores cuentan con todos los servicios, por lo que superan los indicadores de la dimensión pues se encuentran en zonas donde se tiene agua entubada, drenaje, energía eléctrica y están construidas con pisos de cerámica o concreto.

Respecto al financiamiento otorgado a los socios, pudo constatarse que de acuerdo a la información de las cooperativas, del total de los créditos otorgados en un ejercicio contable más del 50\% se destinan a la adquisición, mejora o ampliación de casas - habitación. Sin embargo, no

REVESCO N 106 - Tercer Cuatrimestre 2011 - ISSN: 1885-8031 - www.ucm.es/info/revesco 
se solicitan evidencias de que el crédito se destinó a tal fin, por lo que no fue posible constatar que las mejoras en las viviendas de los socios sean debido a los créditos concedidos.

\section{Dispersión poblacional}

La dispersión geográfica es un grave problema que limita a la población en sus posibilidades de alcanzar igualdad de oportunidades accediendo al desarrollo y sus beneficios, dado que al habitar en regiones alejadas las personas limitan su acceso a ingresos, educación y vivienda adecuada. Para el análisis de esta dimensión se consideró que la misma tiene que ver con el difícil acceso a servicios básicos, pues aunque las cooperativas se han ubicado donde existe mayor concentración poblacional, la mayor parte de las localidades son pequeñas y ubicadas en zonas poco accesibles. La problemática que viven las personas que habitan en regiones dispersas no tiene una solución sencilla, pues es prácticamente imposible para las autoridades gubernamentales formular estrategias encaminadas a lograr la reubicación de poblaciones por el arraigo que tienen las personas a sus comunidades.

En opinión de directivos de la Caja Fátima y San Miguel Palmas, es poco probable que se alcance mayor crecimiento en sus cooperativas, debido a la intrincada ubicación geográfica de los municipios, por lo que no se contempla la apertura de sucursales ya que de hacerlo se incrementarían los costos de operación pues no se cuentan con mecanismos eficaces para la protección de valores.

\section{CONCLUSIONES}

Las oportunidades que tienen las personas son diferentes de una región a otra, es indiscutible que algunos países se encuentran mejor posicionados para aprovechar las oportunidades de una economía global. En México diversos factores restringen el desarrollo económico, la pobreza de ingresos es uno de ellos, pero además existen otros, como el limitado acceso a los mercados financieros, la precaria salud de los habitantes, la educación de baja calidad y la inestabilidad en el campo laboral.

REVESCO No 106 - Tercer Cuatrimestre 2011 - ISSN: 1885-8031 - www.ucm.es/info/revesco 
Las cooperativas de ahorro y préstamo se erigen en una de las opciones para generar oportunidades y dinamizar la economía con una visión centrada en la persona y el desarrollo de las comunidades, ya que para atender problemáticas tan complejas y revertir los efectos de la marginación hace falta la colaboración decidida de los actores públicos, privados y sociales. Es insoslayable que la participación de miembros de la iglesia católica, ha sido fuente inspiradora para la creación de las empresas sociales que se han desarrollado en contextos locales para luego extenderse a otras regiones.

Las evidencias muestran que las cooperativas queretanas que llevan a cabo actividades financieras en municipios de alta y muy alta marginación, representan la única alternativa de financiamiento para la población; en su operación ha sido fundamental el compromiso de sus socios y la participación de los directivos, quienes de manera voluntaria han venido llevando a cabo actividades que contribuyen a la buena marcha de las cooperativas.

Las cooperativas de ahorro y préstamo estudiadas son el ejemplo de que mediante el acceso a fuentes de financiamiento y trabajo es posible superar las carencias; aunque se reconoce que las cooperativas proporcionan trabajo a una cantidad reducida de habitantes, los sueldos percibidos por los empleados de las cooperativas superan el indicador referido a población ocupada. Por su parte, los socios que obtienen créditos para adquirir o mejorar sus viviendas o establecer micro empresas, desarrollado habilidades emprendedoras a través de la creación de empresas dedicadas a la producción, consumo y servicios.

Puede afirmarse que en la medida que la población que habita en regiones marginadas tenga acceso a ingresos por trabajo, será posible mejorar el entorno en el que se desarrolla y podrá acceder a educación, vivienda y servicios de salud adecuados. Se concluye, que las cooperativas de ahorro y crédito constituyen una estrategia de desarrollo local pertinente para el avance social y económico de las comunidades marginadas en tanto formen parte de un proyecto integral que incluya estrategias para la mejora social y económica de sus habitantes.

REVESCO No 106 - Tercer Cuatrimestre 2011 - ISSN: 1885-8031 - www.ucm.es/info/revesco 


\section{BIBLIOGRAFÍA}

ALBURQUERQUE, Francisco. Desarrollo económico local y descentralización en América Latina. Revista Cepal [en línea], núm. 82, 2004, p. 157-171 [23/11/2009]. Disponible en Internet: http://www.eclac.org/cgibin/getProd.asp?xml=/revista/noticias/articuloCEPAL/3/19413/P19413.xml\&xsl=/revista/tpl/ p39f.xsl\&base=/revista/tpl/top-bottom.xslt. ISSN 1682 - 0908.

AMEALCO DE BONFIL. Datos generales y demográficos, 2005. Disponible en Internet: http://queretaro.gob.mx/sedesu/deseco/esteco/perfeco/municipios/amealco.htm. [30/01/2008].

ANZALDO, Carlos y Minerva PRADO. Índices de marginación 2005. Disponible en Internet: http://www.conapo.gob.mx/publicaciones/margina2005/01_b.pdf. 1ª ed. México: CONAPO, 2005, páginas 1-51. ISBN: 970-628-847-3.

AROCENA, José. El desarrollo local. Un desafió contemporáneo. $1^{\mathrm{a}}$ ed. Venezuela: Editorial Nueva Sociedad, 1995. 175 páginas. ISBN 9789803170776.

BANCO DE MÉXICO. Reporte sobre el Sistema Financiero, junio de 2010. Noviembre 2010. Disponible en Internet: http://www.banxico.org.mx/dyn/publicaciones-ydiscursos/publicaciones/informes-periodicos/reporte-sf/\%7BDC37ABCB-26F0-020D-145B5CF397D62E68\%7D.pdf. [20/10/2010].

BANCO MUNDIAL. Censo de las Sociedades con Actividades de Ahorro y Crédito Popular, Octubre de 2001 - Junio de 2002. Resumen Ejecutivo World Bank - Bansefi. Disponible en Internet: http://www.bansefi.mx. Fecha de consulta. [13/06/2003].

CAMPOY LOZAR, Margarita. Marginación y Pobreza. Revista del Ministerio de Trabajo y Asuntos Sociales [en línea], núm. 35, 2002, p. 67-82 [20/07/2009]. Disponible en Internet: http://www.mtas.es/Publica/revista/numeros/35/estudio4.pdf. ISSN 1137-5868.

CÁRDENAS, Nersa. El desarrollo local su conceptualización y procesos. Revista Provincia [en línea], núm. 008, enero-junio 2002, p. 53-76 [20/09/2009]. Disponible en Internet: http://redalyc.uaemex.mx/redalyc/src/inicio/ArtPdfRed.jsp?iCve=55500804. ISSN 13179535.

COMISIÓN NACIONAL BANCARIA Y DE VALORES. Las ventajas de la LRASCAP y el sentido de la regulación prudencial. Enero 2010. Disponible en Internet: 
http://www.cnbv.gob.mx/sectorpopularuc/EstudiosyAcceso/Lista\%20SOCAP\%20Estudios/2 0100127\%20SACP.pdf. [24/10/2010].

CONEVAL. Comunicado Núm. 006/09. Reporta CONEVAL cifras de pobreza por ingresos 2008. Disponible en Internet: http://www.coneval.gob.mx/coneval2/htmls/sala_prensa/HomeSalaPrensa.jsp?id=estimacione s_de_pobreza_por_ingresos_2008. [06/07/2009].

DGRV. The history of cooperatives 2009. Disponible en Internet: http://www.dgrv.de/en/cooperatives/historyofcooperatives.html. [30/06/2009].

DICCIONARIO DE LA LENGUA ESPAÑOLA. Definición de local. Vigésima segunda edición (2001) [en línea]. Disponible en Internet: http://buscon.rae.es/draeI/.

ENCICLOPEDIA DE LOS MUNICIPIOS DE MÉXICO. Municipios de Querétaro, 2009. Disponible en Internet: http://www.e-local.gob.mx/wb2/ELOCAL/EMM_queretaro. [15/03/2009].

ESTIMACIONES DEL CONAPO CON BASE EN EL II CONTEO DE POBLACIÓN Y VIVIENDA 2005 Y ENCUESTA NACIONAL DE OCUPACIÓN Y EMPLEO 2005 (IV Trimestre). Disponible en Internet: www.conapo.gob.mx/publicaciones/margina2005/AnexoB.xls. [10/02/2008].

GOLDIN, Ian y Kenneth REINERT. Globalización para el Desarrollo. $1^{\text {a }}$ ed. Colombia: Editorial Planeta, 2007. 379 páginas. ISBN 9789584215147.

JÁUREGUI, Luis. "Las reformas borbónicas", en Nueva Historia Mínima de México, Daniel Cosío Villegas (coord.) 5a ed. México: El Colegio de México, 2008. 315 pág. ISBN: 9681211391

LAFLEUR, Michael. Desarrollo económico y cooperativas: Un modelo de gestión alternativa. Universidad de Sherbrooke 2005. Documento interno. Agence Canadienne de Développement International. [01/08/2005].

LEY PARA REGULAR LAS ACTIVIDADES DE LAS SOCIEDADES COOPERATIVAS DE AHORRO Y PRÉSTAMO. Congreso de la Unión. 13 de agosto de 2009. Disponible en Internet: [24/10/2009].

NOYA, Antonella. Desarrollo local integrado y economía social. Cuadernos de Economía Social (CEPES) [en línea], núm. 2, 2007, p. 1-3 [23/11/2009]. Disponible en Internet: http://www.cepes.es/media/docs/C.ES-07-\%20n2-DESARROLLO\%20LOCAL.pdf.

REVESCO No 106 - Tercer Cuatrimestre 2011 - ISSN: 1885-8031 - www.ucm.es/info/revesco 
PRÉVOST, Paul. El desarrollo local y las cooperativas. Cuadernos de Desarrollo Rural [en línea], Núm. 37, segundo semestre, segundo semestre 1996, p. 25-45. [03/08/2009]. Disponible en Internet: http://redalyc.uaemex.mx/redalyc/pdf/117/11705507.pdf. ISSN 01221450 .

ROJAS CORIA, Rosendo. Tratado de Cooperativismo Mexicano. $3^{\mathrm{a}}$ ed. México: Fondo de Cultura Económica. 1984. 695 pág. ISBN-13: 978-9681608774

SANCHIS PALACIO, Joan Ramón. Las estrategias de desarrollo local: aproximación metodológica desde una perspectiva socioeconómica e integral. Revista de Dirección, Organización y Administración de Empresas [en línea], núm. 21, enero de 1999, pp. 147-160 [12/08/2009]. Disponible en Internet: http://www.cepade.es/Ademas/fr_pdf.asp?num=21\&artic=14. ISSN 1132-175X.

STIGLITZ, Joseph E. Cómo hacer que funcione la globalización. $1^{\mathrm{a}}$ ed. México: Editorial Taurus, 2006, 440 páginas. ISBN 9707707321.

YIN, Robert K. Case Study Research: Design and Methods. 1a ed. USA: SAGE Publications, 1984. 160 pág. ISBN 0803920571. 